\title{
A SURVEY ON RICE LEAF AND SEEDLINGS DISEASE DETECTION SYSTEM
}

\author{
Devchand J. Chaudhari \\ Research Scholar, Department of Computer Science and Engineering, Saveetha School of Engineering, \\ Saveetha Institute of Medical and Technical Sciences, Chennai, Tamilnadu, India. \\ djchaudhari73@gmail.com \\ K. Malathi \\ Associate Professor, Department of Computer Science and Engineering, Saveetha School of Engineering, \\ Saveetha Institute of Medical and Technical Sciences, Chennai, Tamilnadu, India. \\ malathi@saveetha.com
}

\begin{abstract}
Rice is a major crop in India. Near about $70 \%$, the economy depends on agriculture products. However, Agriculture production is uncertain due to natural calamities, environmental conditions, and unpredictable plant diseases. Plant diseases are nearly impossible to recognize by the open eye by the farmers and crop producers. Therefore, an automatic detection system is a modern approach. Many automatic plant disease detection systems are developing by the researchers. In this paper, we present a summary of different image processing and machine learning techniques applied to the recognition of rice leaf and seedling diseases. Various attributes considered for doing a survey include segmentation type, segmentation techniques, features extracted, dataset size, author's name, and publication year, category of disease, techniques used, detection/classification accuracy, and future scope/limitations. We have gone through several research papers and a brief review of recent image processing and machine-learning techniques used by the researchers has been provided for the rice leaf and seedlings disease detection and classification.
\end{abstract}

Keywords: image segmentation, machine learning, classification, detection, rice disease, seedling.

\section{Introduction}

Rice is a major crop in India. Near about 70\%, the economy depends on agriculture products. However, agriculture production is uncertain due to natural calamities, environmental conditions, and unpredictable plant diseases. Plant diseases are very difficult to detect and classify by the naked eye by the farmers and product producers. Therefore, an automatic detection system is a modern approach. Rice disease detection and classification model consists of the following three steps [Prajapati, et al. (2017)]. In the first step, the segmentation technique used to obtain the diseased part from the healthy part of an image. In the second step, useful features retrieved from the object for classification. In the last step, classification techniques used for the classification of different types of diseases according to the features provided as input [Phadikar, et al. (2012)].

First, we present a review on image processing techniques that use different segmentation techniques such as clustering, thresholding, and the watershed, etc. and feature extraction techniques such as GLCM, HAAR wavelet, etc. to process input image data. Then we present a review on machine learning techniques such as R-CNN, ANN, SVM, Naive Bayes, PNN, Rule Generation Techniques, Decision Tree, and Random Forest that highlight on year of the publication, types of diseases, detection/classification accuracy, future scope and limitations of the current research work.

In this paper, we present a review of different approaches and techniques based on certain parameters. These parameters include segmentation type, segmentation techniques used, features extracted, dataset size, author's name, and publication year, category of disease, algorithm/techniques used, detection/classification accuracy, and future scope/limitations. Twenty-one papers of the last eight years considered on rice leaf and seedling diseases for doing a survey from the year 2012 to 2020 .

Further part of the paper arranged as follows: Section 2 describes the diseases types and their symptoms, image processing steps and machine learning steps used in research papers. Section 3 describes literature survey. Section 4 describes a summary of image processing techniques used in rice disease detection. Section 5 describes a summary of machine learning techniques used for rice disease classification and conclusions are discussed in section 6 . 


\section{Background}

In this section, we provide some background information related to our work.

\subsection{Rice diseases and their symptoms}

In this section, we explain different rice diseases and their symptoms briefly [Groth, et al. (1914)].

1. Rice Leaf Blast: Symptoms of this disease are dark to oval spots with a reddish-brown margin [Groth, et al. (1914)][Shah, et al. (2016)].

2. Brown spot: Symptoms of this disease are round to oval, dark-brown color spot [Groth, et al. (1914)][Shah, et al. (2016)].

3. Narrow brown leaf spot: The symptoms of this disease are long narrow or reddish-brown lesions. Lesions are on leaf sheaths. Under favorable conditions, it expands lesions across veins and leaves may damage [Groth, et al. (1914)].

4. Sheath blight: Lesions are oval with reddish-brown spots. Under favorable conditions, birds nest areas may form [Groth, et al. (1914)].

5. Leaf scald: Lesions with Reddish and brown large bands [Groth, et al. (1914)].

6. Bacterial leaf blight: Lesions include prolonged lesions near the tip or margin of the leaf. Lesions are long, and it turns to yellow due to the implication of fungi [Groth, et al. (1914)].

7. Sheath rot: Symptoms of this disease are a reddish-brown stain on leaf sheath [Groth, et al. (1914)].

8. Leaf smut: Lesions are small black on the leaf blades. Dark gold or brown halo lesions [Groth, et al. (1914)].

9. Seedling Blight: Brown spot on a sheath or growing the point, seedling suddenly dying [Groth, et al. (1914)].

\subsection{Steps in image processing}

Following steps are required in image processing [Rafael, and Richard, (1997)].

\subsubsection{Image acquisition}

In this method, images collected from the field with the help of a digital or mobile camera, and then different image processing techniques can be applied.

\subsubsection{Image preprocessing}

For obtaining good performance in disease detection and classification process, preprocessing of images are needed because images come with various noises and unwanted parts. Sometimes, images may come with water droplets and dimness effects. The effect of such perversion can be reduced or eliminated using noise elimination techniques. There may be a need for image enhancement using available techniques.

\subsubsection{Image segmentation}

Segmentation technique applied to find particular regions of interest or object. In the literature survey paper, various segmentation techniques such as k-means clustering, Otsu's threshold method [Larijani, et al. (2019)], Pixel-based, Fermi Energy, Fractal Descriptors, and watershed methods are used [Yang, et al. (2019)].

\subsubsection{Feature extraction}

The feature extraction technique [Prajapati, et al. (2017)] is used to collect immanent characteristics or features of given objects. These features are then used as an input to classify the object. In the literature survey, the following categories of features are extracted: statistical, color, shape, texture, wavelets, size, area, proximity, and centroids, morphology features, correlation-based feature, textural descriptors using GLCM and color moments.

\subsubsection{Classification}

Classification represents grouping the data into specific categories or classes. Various classification algorithms used are SVM, artificial neural network, decision tree, k-NN, and rule-based techniques.

\subsection{Steps in machine learning}

It is not possible manually to detect diseases. Plant diseases are very difficult to detect and classify by the naked eye by the farmers and product producers. Therefore, an automatic detection system is a modern approach.

Machine learning algorithms are classified in the following four types: supervised learning, unsupervised learning, semi-supervised learning, and reinforcement learning [Tom, (1997)]. The following steps are required to carry out classification. 


\subsubsection{Gathering data}

In this step, we gather the data. This is very important because the quality and quantity of data will decide how good your predictive model can be.

\subsubsection{Data preparation}

Collected data is not very useful. It needs to be prepared, normalized, and remove errors before using it. Needs to be converting into the required format.

\subsubsection{Choosing a model}

This step consists of choosing the correct model. Choosing an appropriate algorithm is very important because our prediction accuracy depends on the chosen model.

\subsubsection{Training the model}

Given a set of inputs, the training consists of the construction of the computational model [Diego, et al. (2018)]. In this step, training data used to improve the ability of the model incrementally. In general, we can use $80 \%$ of data for training and $20 \%$ of data for Evaluation.

Machine Learning is a much more diverging tool that uses the performance of already existing neural network techniques to provide a generic algorithm that can recognize or identify certain features in the given input. Following Machine Learning Algorithms are used in survey papers - ANN, Genetic Algorithm, SVM, Decision Tree, K-NN, R-CNN, Feed forward Neural Network, Naïve Bayes and Logistic Regression, MDC, Back Propagation Neural Network, Rule generation classifier, Texture Analysis, and Probabilistic Neural Network (PNN).

\section{Related Work}

This section describes several research contributions that have already contributed by researchers related to rice leaf and seedlings disease detection and classification. The literature used in this survey paper is from 2012 to 2020, that is, the last 8 years. this section.

We have gone through several research papers and the outcome belongs to these results as presented in

[Pothen, and Pai, (2020)] proposed a system to detect Bacterial blight, Leaf smut, and Brown Spot. Features obtained from LBP and Support Vector Machine uses HOG for classification. Otsu's segmentation technique used and separate the infected part from the healthy portion. Segmentation using Otsu's method finds the best value for the threshold. Otsu method divides the image into the number of segments by grouping pixels that correspond to the objects in an image. Three Kernel functions like Linear, Polynomial, and Radial Basis Function (RBF) used with SVM to train the data.

[Yang, et al. (2019)] presented a system to detect rice and rice blast diseases. In this paper, the microscopy image used as an input and identifies the diseases. Watershed method used for the segmentation of backer spores in images. Texture and shape features extracted and provide as an input to the decision tree model for classification. Classification accuracy measured by using the confusion matrix method and achieved detection accuracy was $94 \%$.

[Mohammad, et al. (2019)] presents an early detection of rice blast disease using image-processing techniques. In this paper, improved k-NN along with K-means applied to classify the diseases in lab color space. The segmentation techniques used for partitioned images were the Otsu method. Shape and color features extracted and used for the classification. Sensitivity, specificity, and accuracy used for calculating the effectiveness of the k-NN algorithm combined with k-means. The accuracy achieved by the depicted algorithm was $94 \%$.

[Nidhis, et al. (2019)] proposed a system to detect Bacterial blight, Rice Leaf Blast, and Brown Spot using image-processing techniques. In this paper, $\mathrm{k}$-means clustering used to separate the damaged portions from the undamaged portion of the leaf. Point feature matching technique applied for disease detection. Features like color, size, centroids, and proximity used for the categorization of types of diseases.

[Zhou, et al. (2019)] proposed a system to identify and classify Rice blast, bacterial blight, and sheath blight diseases. Otsu's threshold technique used to weaken the interference of the background portion with the finding of the required region. FCM-KM algorithm used to calculate the best values of k. Combination of FCMKM and Faster R-CNN used for recognition of rice diseases. Disease detection accuracy achieved for rice blast, bacterial blight, and blight was $96.71 \%, 97.53 \%$, and $98.26 \%$ respectively.

[Shreekanth, et al. (2019)] proposed a system to identify Leaf Blast, Brown Spot, and Leaf Blight diseases in paddy leaf. Otsu's method applied for the partition of the image. Wavelets and texture feature used for classification. Classification performed by using a feed-forward neural network (FFNN). Accuracy of classification was $83.3 \%$ for 3 types of diseases and $100 \%$ accuracy for 2 types of diseases.

[Kawcher, et al. (2019)] purpose of this work is to detect diseases such as Bacterial Blight, Brown Spot and Leaf Smut, using four different machine learning algorithms such as K-Nearest Neighbour, Naive Bayes, 
Logistic Regression and Decision Tree. The accuracy of disease detection achieved from this model was 97\% after 10-fold cross-validation. In this paper, attributes (features) were extracted using a correlation-based feature selection method.

[Bakar, et al. (2018)] proposed a system to detect Rice Leaf Blast disease, and it also classifies the severity of disease into three different stages like infection, spreading, and worst stage. In this work, the HSV color space is used. Multi-Level thresholding technique applied to find the region of interest. Shape and Color features extracted. This model is not suitable for the identification of other diseases that may have identical traits.

[Ramesh, and Vydeki, (2018)] proposed a system that presents a machine learning technique used for early detection of Rice Leaf Blast disease. K-means clustering algorithm used to separate damaged portion from the healthy portion of the image. Statistical and texture features are used to distinguish healthy and diseaseaffected leaves. ANN algorithm used for the classification of infected and healthy leaf images.

[Zhang, et al. (2018)] proposed a system to detect three types of rice blast lesion namely acute type, chronic type, and white type respectively. Otsu's method used for segmentation. Color, and morphology features are used for classification. SVM classifier with Radial Basis Function (RBF) is used for the classification of three types of rice blast lesion. The average accuracy of classification achieved is $95.6 \%$ after 5 fold cross-validation. The segmentation algorithm and feature extraction techniques used in this work may also use for identical crops.

[Islam, et al. (2018)] proposed a method to detect and classify the types of disease such as Rice Leaf Blast, Brown spot, and Bacterial blight. It uses a percentage of RGB value as an input for classification using Naive Bayes classifier into different types of diseases. It does not specify any segmentation technique. The accuracy of this model is above $89 \%$ for Rice blast disease and above $90 \%$ for Bacterial Blight, and Rice Brown Spot disease.

[Prajapati, et al. (2017)] proposed a system for the identification of Bacterial blight, Brown spot, and Leaf Smut. K-means clustering algorithm applied for the segmentation and enhanced output of segmentation by eliminating green pixels from the damaged region. Color, shape, and texture features are used as input for classification by the Support Vector Machine. The accuracy achieved is $93.33 \%$ on training and $73.33 \%$ on test datasets. They achieved $83.80 \%$ and $88.57 \%$ accuracy, after 5 and 10 -fold cross-validations, respectively.

[Pinki, et al. (2017)] proposed a system for recognition of Bacterial Blight, Rice Leaf Blast, and Brown Spot diseases. It also gives advice to farmers for the use of pesticides and fertilizers. K-means clustering algorithm used to separate diseased regions from the healthy region of the image. Color, shape, and texture features are used as input for classification by the SVM. It also calculates the severity of the disease by determining the percentage of the damaged portion.

[Narmadha, et al. (2017)] purpose of this work is to detect and identify Rice Blast, Brown spot, and Narrow Brown spot diseases using image processing techniques. K-means clustering used to separate unwanted portions and noise from the image, and it detects diseases. It uses shape and color features for classification using ANN and Fuzzy Classification. In this work, accuracy not specified.

[Ghyar, and Birajdar, (2017)] present a system for automatic detection of Rice Leaf Blast, and Brown Spot disease using texture and color descriptors. Three features like area, texture descriptors, and color moments are considered for classification. Features are selected using a genetic algorithm. SVM and ANN classifiers are used in this system. SVM provides $92.5 \%$ accuracy and ANN provides $87.5 \%$ accuracy.

[Joshi, and Jadhav, (2016)] presents a system for the detection of Rice Leaf Blast, Bacterial Blight, Brown Spot, and Sheath Rot. Color and shape features were used for classification. Two classifiers, K-NN and MDC (Minimum Distance Classifier) used in this system. K-NN achieved 87.02 \% accuracy and MDC achieved $89.23 \%$ classification accuracy.

[Chung, et al. (2016)] proposed a system to classify unhealthy and healthy seedlings. 3-week old seedlings used for this work. The seedlings were prepared in an incubator for 3 weeks. Using a flatbed scanner, images of infected seedlings were scanned. The thresholding technique used for segmentation. Essential traits and parameters are used as input to the SVM classifiers. A support vector machine (SVM) used as a classifier for differentiating infected seedlings from healthy seedlings. Two classifiers used in a cascade manner for classification. Parameters selected using a genetic algorithm. In this work, an accuracy achieved is $87.9 \%$.

[William, et al. (2014)] proposed a system to detect rice disease more accurately by using image processing and the Artificial Neural Network algorithm. Back Propagation neural network used for disease identification and increase the accuracy, and the performance of the image-processing algorithm. It also suggests a recommendation for quick relief and tactical planning for the next plantation. Otsu's method is used for the segmentation. Features such as area, mean, and standard deviation extracted and used for the classification. Back-propagation Neural Network algorithm is used. Accuracy was $100 \%$.

[Asfarian, et al. (2013)] proposed a system to identify four rice diseases namely Rice Leaf Blast, Brown spot, Bacterial leaf blight, and tungro. It uses fractal descriptors to study the texture of the lesions. Diseased images extracted manually and used as input for the identification of disease. The descriptors of lesion 
images are used for classification as input using probabilistic neural networks. This approach achieved $83 \%$ disease identification accuracy.

[Phadikar, et al. (2013)] purpose of this research work is to identify Rice Leaf Blast, Brown Spot, Bacterial blight, and Sheath rot. Fermi energy technique applied to separate the diseased region. Genetic Algorithm applied to find the infected region. Using a novel techniques color, shape, and position features extracted and used for the classification of diseases. Important features are selected to diminish the intricacy of the classifier using rough set theory (RST). A rule-based technique used for classifying the diseases.

[Phadikar, et al. (2012)] proposed a system used for detecting Rice Leaf blast, and Rice brown spot using a morphological change in a leaf. The radial distribution features used as an input for the classification. Bayes and SVM used for the classification. Bayes achieved an accuracy of 79.5\% and SVM achieved $68.1 \%$. Preprocessing of images required before classification and detection.

\section{Summary of Image Processing Techniques used in Rice Disease Detection}

In this section, we present different image processing techniques implemented in research works on rice disease identification by the researchers. We used a total of 21 research papers of the last eight years on rice leaf and seedling disease by considering parameters such as segmentation type, segmentation techniques, features extracted, dataset size, and image background. Table-1. Presents summary of different image processing techniques used in rice disease detection.

Table 1. Summary of Image Processing Techniques Used in Rice Disease Detection

\begin{tabular}{|c|c|c|c|c|}
\hline Ref. & $\begin{array}{l}\text { Segmentation } \\
\text { Type }\end{array}$ & Techniques used & Extracted features & Size of dataset \\
\hline [21] & Thresholding & Otsu's Method & Texture Features(LBP) & 120 images \\
\hline [29] & Watershed & Distance transformation & Texture and Shape & $\begin{array}{ll}2000 & \text { microscopic } \\
\text { images } & \\
\end{array}$ \\
\hline [10] & $\begin{array}{ll}\text { Clustering } & \text { and } \\
\text { Thresholding } & \end{array}$ & K-means and Otsu method & Shape and Color & 500 sample images \\
\hline [16] & Clustering & K-means & size, color, proximity, and centroids & Not specified. \\
\hline$[30]$ & $\begin{array}{ll}\text { Clustering } & \text { and } \\
\text { Thresholding } & \\
\end{array}$ & K-means and Otsu method & Texture, color, and shape & 3010 images \\
\hline [24] & Thresholding & Otsu's Method & Texture and Wavelets & Not specified \\
\hline [9] & Not Specified & Not Specified & Correlation Based Feature & 480 images \\
\hline [2] & $\begin{array}{l}\text { Multi-Level } \\
\text { Thresholding }\end{array}$ & Pixel-based & Shape and Color & Not Specified \\
\hline [22] & Clustering & K-means & Statistical and Texture & 300 images \\
\hline [31] & Thresholding & Otsu's Method & Morphology and color & 90 images \\
\hline [7] & Not Specified & Not Specified & RGB values & 60 images \\
\hline [19] & Clustering & K-means & Color, shape, and texture & Not specified. \\
\hline [20] & Clustering & K-means & Color, texture, and shape & Not specified \\
\hline$[15]$ & Clustering & K-means & Shape and color & Not specified \\
\hline [5] & Clustering & K-means & $\begin{array}{l}\text { Area, texture descriptors using } \\
\text { GLCM, and color moments }\end{array}$ & Not specified \\
\hline [8] & Clustering & YCbCr color space & Shape and Color & 115 images \\
\hline [3] & Thresholding & -- & Morphological and color traits & 700 images \\
\hline [28] & Thresholding & Otsu's Method & Statistical features and fraction(area) & 134 images \\
\hline [1] & Fractal Descriptors & Multiscale transform & Color & 40 images \\
\hline [17] & $\begin{array}{l}\text { Thresholding and } \\
\text { Clustering }\end{array}$ & $\begin{array}{l}\text { K-means, Otsu method, and Fermi } \\
\text { energy based }\end{array}$ & Color, shape and position & 500 images \\
\hline [18] & Thresholding & Otsu's method & Radial hue distribution & 1000 images \\
\hline
\end{tabular}

\section{Summary of Machine Learning Operations used in Rice Disease Detection and Classification}

This section presents a survey of different machine learning [Tom, (1997)] algorithms applied to rice disease detection and classification. In this survey, we considered the following parameters like the author's name, and publication year, category of disease, techniques used, detection/classification accuracy, limitations, and future scope of their research work. Table-2. Presents the summary of various machine learning [Tom, (1997)] operations used in rice diseases detection and classification. 
Table 2. Summary of Various Machine-Learning Operations Used in Rice Disease Detection and Classification

\begin{tabular}{|c|c|c|c|c|c|}
\hline $\begin{array}{l}\text { Author's } \\
\text { name }\end{array}$ & $\begin{array}{l}\text { Year of the } \\
\text { publication }\end{array}$ & $\begin{array}{l}\text { Types } \\
\text { Diseases }\end{array}$ & $\begin{array}{l}\text { Applied } \\
\text { Technique } \\
\text { /Algorithm }\end{array}$ & $\begin{array}{l}\text { Detection/ } \\
\text { Classification } \\
\text { Accuracy }\end{array}$ & Limitations/ Future Scopes \\
\hline $\begin{array}{l}\text { Pothen } \\
\text { Minu Eliz et } \\
\text { al. [21] }\end{array}$ & $(2020)$ & $\begin{array}{l}\text { Bacterial blight, } \\
\text { Leaf Smut and } \\
\text { Brown Spot }\end{array}$ & SVM & $94.6 \%$ & $\begin{array}{l}\text { 1. Only three diseases are considered. } \\
\text { 2. Database extension needed in order } \\
\text { to reach more accuracy. }\end{array}$ \\
\hline $\begin{array}{l}\text { Yang Ning et } \\
\text { al.[29] }\end{array}$ & (2019) & $\begin{array}{l}\text { Rice Smut, and } \\
\text { Rice Blast }\end{array}$ & DT & $94 \%$ & $\begin{array}{l}\text { 1. Obtaining a microscopic image and } \\
\text { microscopic image acquisition is } \\
\text { difficult and complicated. } \\
\text { 2. It is used to detect only two types of } \\
\text { diseases. } \\
3 \text {. Accuracy is less }(94 \%) \text {. }\end{array}$ \\
\hline $\begin{array}{l}\text { Larijani } \\
\text { Mohammad } \\
\text { Reza et al. } \\
{[10]}\end{array}$ & (2019) & Rice Blast & KNN & $94 \%$ & $\begin{array}{l}\text { 1. It is used only to detect Rice Blast } \\
\text { Disease. } \\
\text { 2. No comparison with other } \\
\text { classifier }\end{array}$ \\
\hline $\begin{array}{l}\text { Nidhis A. D. } \\
\text { et al. [16] }\end{array}$ & (2019) & $\begin{array}{l}\text { Rice Blast, } \\
\text { Brown Spot, and } \\
\text { Bacterial Blight }\end{array}$ & $\begin{array}{l}\text { k-means } \\
\text { clustering }\end{array}$ & Not specified & $\begin{array}{l}\text { 1. Accuracy is not specified. } \\
\text { 2. Dataset size is not specified. } \\
\text { 3. Only three diseases are covered. }\end{array}$ \\
\hline $\begin{array}{l}\text { Zhou } \\
\text { Guoxiong et } \\
\text { al. [30] }\end{array}$ & (2019) & $\begin{array}{l}\text { Rice blast, } \\
\text { Sheath blight, } \\
\text { and Bacterial } \\
\text { blight }\end{array}$ & R-CNN & $97.2 \%$ & $\begin{array}{l}\text { 1. It is not suitable for monitoring } \\
\text { large-scale rice farming. } \\
\text { 2. Complexity is more. }\end{array}$ \\
\hline $\begin{array}{l}\text { Shreekanth K. } \\
\text { N. et al. [24] }\end{array}$ & (2019) & $\begin{array}{l}\text { Leaf Blast, } \\
\text { Brown Spot and } \\
\text { Leaf Blight }\end{array}$ & $\begin{array}{l}\text { Feed forward } \\
\text { NN }\end{array}$ & $\begin{array}{l}83.3 \% \text { for three } \\
\text { and } 100 \% \text { for two } \\
\text { types of diseases. }\end{array}$ & $\begin{array}{l}\text { 1. Size of dataset is not specified. } \\
\text { 2. Success rate is low for dataset of } \\
\text { three types of diseases. } \\
\text { 3. Only three diseases are covered. }\end{array}$ \\
\hline $\begin{array}{l}\text { Kawcher } \\
\text { Ahmed et al. } \\
\text { [9] }\end{array}$ & (2019) & $\begin{array}{l}\text { Bacterial Blight, } \\
\text { Leaf Smut, and } \\
\text { Brown Spot }\end{array}$ & $\begin{array}{l}\text { K-NN, DT, } \\
\text { Naive Bayes } \\
\text { and Logistic } \\
\text { Regression }\end{array}$ & $97 \%$ & $\begin{array}{l}\text { 1. It predicted the rice leaf diseases } \\
\text { with greater or lesser accuracy. } \\
\text { 2. Quality of datasets can be } \\
\text { improved. } \\
\text { 3. Need to analyze the performance of } \\
\text { learning methods. }\end{array}$ \\
\hline $\begin{array}{l}\text { Bakar Abu } \\
\text { M.N. et al. [2] }\end{array}$ & (2018) & Rice Blast & $\begin{array}{l}\text { Multi-Level } \\
\text { Thresholding }\end{array}$ & Not specified & $\begin{array}{l}\text { 1. Only one Rice disease is covered. } \\
\text { 2. The technique is not suitable for } \\
\text { detection of other diseases which may } \\
\text { have similar features. }\end{array}$ \\
\hline $\begin{array}{l}\text { Ramesh S. et } \\
\text { al. [22] }\end{array}$ & $(2018)$ & Rice Blast & ANN & $\begin{array}{l}90 \% \text { for the } \\
\text { infected images } \\
\text { and } 86 \% \text { for the } \\
\text { healthy images }\end{array}$ & $\begin{array}{l}\text { 1. It used only for detecting Rice Blast } \\
\text { Disease. } \\
\text { 2. It distinguishes only the healthy and } \\
\text { unhealthy leaves. } \\
\text { 3. It will not classify types of diseases. }\end{array}$ \\
\hline $\begin{array}{l}\text { Zhang Jun. et } \\
\text { al. [31] }\end{array}$ & $(2018)$ & Rice Blast & SVM & $95.6 \%$ & $\begin{array}{l}\text { 1. Very small dataset is used } \\
\text { 2. No comparison with other classifier }\end{array}$ \\
\hline $\begin{array}{l}\text { Islam } \\
\text { Taohidul et } \\
\text { al. [7] }\end{array}$ & $(2018)$ & $\begin{array}{l}\text { Rice Blast, } \\
\text { Brown Spot, and } \\
\text { Bacterial Blight }\end{array}$ & Naïve Bayes & $\begin{array}{l}\text { Rice Blast above } \\
89 \% \text {, Brown Spot } \\
\text { above } 90 \% \text {, and } \\
\text { Bacterial Blight } \\
\text { above } 90 \%\end{array}$ & $\begin{array}{l}\text { 1. Dataset is very small. } \\
\text { 2. Segmentation is not used. } \\
\text { 3. Only RGB value features is used. }\end{array}$ \\
\hline $\begin{array}{l}\text { Prajapati H. B. } \\
\text { et al. [19] }\end{array}$ & (2017) & $\begin{array}{l}\text { Bacterial Blight, } \\
\text { Brown Spot, and } \\
\text { Leaf Smut }\end{array}$ & SVM & $\begin{array}{l}\text { Training accuracy } \\
93.33 \%, \text { and } \\
\text { testing accuracy } \\
73.33 \% .\end{array}$ & $\begin{array}{l}\text { 1. Testing accuracy is very less. } \\
2 \text {. Very large set of features are used. }\end{array}$ \\
\hline $\begin{array}{l}\text { Pinki F. T. et } \\
\text { al. [20] }\end{array}$ & (2017) & $\begin{array}{l}\text { Leaf blast, } \\
\text { Bacterial blight } \\
\text { and Brown spot }\end{array}$ & SVM & Not specified & 1. Accuracy is not specified. \\
\hline $\begin{array}{l}\text { Narmadha R. } \\
\text { P. et al. [15] }\end{array}$ & (2017) & $\begin{array}{l}\text { Rice Blast, } \\
\text { Narrow Brown } \\
\text { Spot, and Brown } \\
\text { Spot. }\end{array}$ & $\begin{array}{l}\text { ANN and } \\
\text { Fuzzy } \\
\text { Classification }\end{array}$ & Not specified & $\begin{array}{l}\text { 1. Accuracy is not specified. } \\
\text { 2. Only three diseases are covered. } \\
\text { 3. Implementation details and } \\
\text { Classification of diseases is not } \\
\text { properly explained. } \\
\text { 4. Dataset is not specified. }\end{array}$ \\
\hline $\begin{array}{l}\text { Ghyar } \\
\text { Bhagyashri S. } \\
\text { et al. [5] }\end{array}$ & (2017) & $\begin{array}{l}\text { Leaf Blast and } \\
\text { Brown Spot }\end{array}$ & $\begin{array}{l}\text { ANN and } \\
\text { SVM }\end{array}$ & Not specified & 1. Only two diseases are covered. \\
\hline
\end{tabular}




\begin{tabular}{|c|c|c|c|c|c|}
\hline $\begin{array}{l}\text { Joshi Amrita } \\
\text { A. et al. [8] }\end{array}$ & $(2016)$ & $\begin{array}{l}\text { Rice Blast, } \\
\text { Bacterial Blight, } \\
\text { Brown spot, and } \\
\text { Sheath rot }\end{array}$ & $\begin{array}{l}\mathrm{k}-\mathrm{NN} \text { and } \\
\mathrm{MDC}\end{array}$ & $\begin{array}{l}\text { K-NN accuracy } \\
87.02 \% \text { and } \mathrm{MDC} \\
\text { accuracy } 89.23 \%\end{array}$ & $\begin{array}{l}\text { 1. Dataset is very small. } \\
\text { 2. Segmentation is not properly } \\
\text { mentioned. } \\
\text { 3. More diseases can be covered. }\end{array}$ \\
\hline $\begin{array}{l}\text { Chung Chia- } \\
\text { Lin et al. [3] }\end{array}$ & $(2016)$ & Bakanae & SVM & $87.9 \%$ & $\begin{array}{l}\text { 1. This approach is less subjective and } \\
\text { time-consuming. } \\
\text { 3. Accuracy is less. } \\
\text { 4. Complexity is more. }\end{array}$ \\
\hline $\begin{array}{l}\text { William John } \\
\text { et al. [28] }\end{array}$ & (2014) & $\begin{array}{l}\text { Bacterial Leaf } \\
\text { Blight, Brown } \\
\text { Spot, and Rice } \\
\text { Blast }\end{array}$ & $\begin{array}{l}\text { Back } \\
\text { Propagation } \\
\text { NN }\end{array}$ & $100 \%$ & $\begin{array}{l}\text { 1. Only three diseases are covered. } \\
\text { 2. Dataset size is small. } \\
\text { 3. No performance comparison with } \\
\text { other Neural Network. } \\
\text { 4. Computational cost is high. }\end{array}$ \\
\hline $\begin{array}{l}\text { Asfarian Auzi } \\
\text { et al. [1] }\end{array}$ & $(2013)$ & $\begin{array}{l}\text { Leaf Blast, } \\
\text { Brown Spot, } \\
\text { Bacterial Blight, } \\
\text { and Tungro }\end{array}$ & $\begin{array}{l}\text { Texture } \\
\text { Analysis and } \\
\text { PNN }\end{array}$ & $83 \%$ & $\begin{array}{l}\text { 1. Dataset is very small. } \\
\text { 2. Accuracy can be improved. }\end{array}$ \\
\hline $\begin{array}{l}\text { Phadikar } \\
\text { Santanu et al. } \\
\text { [17] }\end{array}$ & (2013) & $\begin{array}{l}\text { Rice blast, } \\
\text { Brown spot, } \\
\text { Bacterial blight, } \\
\text { and Sheath rot }\end{array}$ & $\begin{array}{l}\text { Rule } \\
\text { generation }\end{array}$ & $90 \%$ & $\begin{array}{l}\text { 1. Computational complexity is more. } \\
\text { 2. Accuracy can be improved. }\end{array}$ \\
\hline $\begin{array}{l}\text { Phadikar } \\
\text { Santanu et al. } \\
{[18]}\end{array}$ & $(2012)$ & $\begin{array}{l}\text { Brown } \\
\text { spot and rice } \\
\text { blast }\end{array}$ & $\begin{array}{l}\text { Naïve Bayes } \\
\text { and SVM }\end{array}$ & $\begin{array}{l}79.5 \% \text { for } \\
\text { Bayes and } 68.1 \% \\
\text { for SVM }\end{array}$ & $\begin{array}{l}\text { 1. Accuracy is very low. } \\
\text { 2. Only two diseases are considered. } \\
\text { 2. Comparison between classifier not } \\
\text { mentioned clearly. }\end{array}$ \\
\hline
\end{tabular}

\section{Conclusion}

Rice is a major crop in India. Rice plant diseases are very difficult to detect and classify by the naked eye by the farmers and product producers. Therefore, an automatic detection system is a modern approach.

In this work, we present a survey of different approaches and techniques applied for the identification and classification of rice leaf and seedling diseases. A total of 21 papers of the last eight years from 2012 to 2020 are considered on rice plant diseases for doing surveys.

In the survey paper, we found that various segmentation techniques such as k-means clustering, Otsu's method, Pixel-based, Fermi Energy, Fractal Descriptors and watershed method are used and statistical, color, shape, texture, wavelets, size, area, proximity, and centroids, morphology features, correlation-based feature, textural descriptors, and color moments features are extracted.

Following Machine Learning Algorithms used in survey papers: ANN, Genetic Algorithm, SVM, Decision Tree, K-NN, R-CNN, Feed-Forward Neural Network, Naïve Bayes, Logistic Regression, Minimum Distance Classifier (MDC), Back Propagation Neural Network, Rule generation technique, Texture Analysis, and Probabilistic Neural Network (PNN). Many authors used the SVM classifier for the classification of diseases when compared with other classifiers. We concluded that SVM and ANN give better accuracy, for the classification of diseases.

\section{References}

[1] Asfarian, A.; Herdiyeni, Y.; Rauf, A.; Mutaqin, K. H. (2013): Paddy Diseases Identification with Texture Analysis using Fractal Descriptors Based on Fourier Spectrum. IEEE International Conference on Computer, Control, Informatics and Its Applications.

[2] Bakar, Abu M. N.; Abdullah, A.H.; Rahim, A. N.; Yazid, H.; Misman, S. N.; Masnan, M. J. (2018): Rice Leaf Blast Disease Detection Using Multi-Level Colour Image Thresholding. Journal of Telecommunication, Electronic and Computer Engineering (JTEC). 10(115), 1-6.

[3] Chung, C.; Huang, K.; Chen, S.; Lai, M.; Chen, Y.; Kuo, Y. (2016): Detecting Bakanae disease in rice seedlings by machine vision. Computers and Electronics in Agriculture. vol. 121, pp. 404-411.

[4] Diego, I. P.; Rafael, R. (2018): Computer vision and artificial intelligence in precision agriculture for grain crops: A systematic review. Computers and Electronics in Agriculture. 153:69-81.

[5] Ghyar, B. S.; Birajdar, G. K. (2017): Computer vision based on approach to detect rice diseases using texture and color descriptors. IEEE International Conference on Inventive Computing and Informatics (ICICI). Part Number: CFP17L34-ART, ISBN: 978-1-53864031-9.

[6] Groth D. and Agcenter L.S.U. Rice Disease Identification Photo Link.

[7] Islam, T.; Sah, M.; Baral, S.; Roychoudhury, R. (2018): A Faster Technique on Rice Disease Detection Using Image Processing of Affected Area In Agro-Field. IEEE International Conference on Inventive Communication and Computational Technologies (ICICCT).

[8] Joshi, A. A.; Jadhav, B. (2016): Monitoring and controlling rice diseases using image processing techniques. IEEE International Conference on Computing, Analytics and Security Trends (CAST). pp.471-476.

[9] Kawcher, A.; Shahidi, T.; Syed, Md. I. A.; Sifat, M. (2019): Rice Leaf Disease Detection Using Machine Learning Techniques. IEEE International Conference on Sustainable Technologies for Industry 4.0 (STI). 24-25. 
[10] Larijani M. R. , Ardeh E. A. A., Kozegar E. and Loni R. 2019. Evaluation of image processing technique in identifying rice blast disease in field conditions based on KNN algorithm improvement by K-means. Food Science \& Nutrition. published by Wiley Periodicals, Inc. Available: 10.1002/fsn3.1251.

[11] Malathi, K.; Nedunchelian, R. (2017): A recursive support vector machine (RSVM) algorithm to detect and classify diabetic retinopathy in fundus retina images. Biomedical Research. Volume Special Issue, pp.1 - 8 ISSN 0970-938X.

[12] Narmadha, R. P.; Arulvadivu, G. (2017): Detection and Measurement of Paddy Leaf Disease Symptoms using Image Processing. IEEE International Conference on Computer Communication and Informatics (ICCCI -2017).

[13] Nidhis, A. D.; Pardhu, C. N. V.; Reddy, K. C.; Deepa, K. (2019): Cluster Based Paddy Leaf Disease Detection, Classification and Diagnosis in Crop Health Monitoring Unit. Lecture Notes in Computational Vision and Biomechanics. Springer Nature, Switzerland AG.

[14] Phadikar, S.; Sil, J.; Das, A. K. (2013): Rice diseases classification using feature selection and rule generation techniques. Computers and Electronics in Agriculture . 90, pp.76-85.

[15] Phadikar, S.; Sil, J.; Das, A.K. (2012): Classification of Rice Leaf Diseases Based on Morphological Changes. International Journal of Information and Electronics Engineering . 2(3), pp.460-463.

[16] Prajapati, H. B.; Shah, J. P.; Dabhi, V. K. (2017): Detection and classification of rice plant diseases. Intelligent Decision Technologies. 11(3), 357-373.

[17] Pinki, F. T.; Khatun, N.; Islam, S. M. M. (2017): Content based Paddy Leaf Disease Recognition and Remedy Prediction using Support Vector Machine. IEEE International Conference of Computer and Information Technology (ICCIT). 22-24, December.

[18] Pothen, M. E.; Pai, M. L. (2020): Detection of Rice Leaf Diseases Using Image Processing. IEEE International Conference on Computing Methodologies and Communication (ICCMC 2020). 978-1-7281-4889-2/20.

[19] Ramesh, S.; Vydeki, D. (2018): Rice Blast Disease Detection and Classification using Machine Learning Algorithm. IEEE International Conference on Micro-Electronics and Telecommunication Engineering.

[20] Rafael, C. G.; Richard, E. (1997): Digital Image Processing. Pearson Education, Third Edition.

[21] Shreekanth, K. N.; Suresha, M.; Naik, H. (2019): A Novel Segmentation and Identification of Diseases in Paddy Leaves Using Color Image Fusion Technique. IEEE International Conference on Image Information Processing (ICIIP). 978-1-7281-0899-5.

[22] Shah, J. P.; Prajapati, H. B.; Dabhi, V. K. (2016): Survey on Detection and Classification of Rice Plant Diseases. IEEE conference on Current Trends in Advanced Computing (ICCTAC). pp.1-8.

[23] Singh, A.K.; Rubiya, A.; Raja, B. S. (2015): Classification of rice disease using digital image processing and svm classifier. International Journal of Electrical and Electronics Engineers. 7(1): 294-299.

[24] Tom M. Mitchell., (1998): Machine Learning. McGraw-Hill Publication. ISBN: 0070428077.

[25] William, J.; Jennifer, D. C.; Leobelle, A.; Paul, J. S.; Valenzuela, I. (2014): Identification of Diseases in Rice Plant (Oryza Sativa) using Back Propagation Artificial Neural Network. IEEE International Conference on HNICEM, pp.12-16.

[26] Yang, N.; Qian, Y.; Mesery, S. E.; Zhang, R.; Wang, A.; Tang, J. (2019): Rapid detection of rice disease using microscopy image. Journal Sci. Food Agri. Published online in Wiley Online Library.

[27] Zhou, G.; Zhang, W.; Chen, A.; He, M. (2019): Rapid Detection of Rice Disease Based on FCM-KM and Faster R-CNN Fusion. IEEE Access. Vol. 7, pp. $143190-143206$.

[28] Zhang, J.; Yan, L.; Hou, J. (2018): Recognition of rice leaf diseases based on salient characteristics. IEEE World Congress on Intelligent Control and Automation.

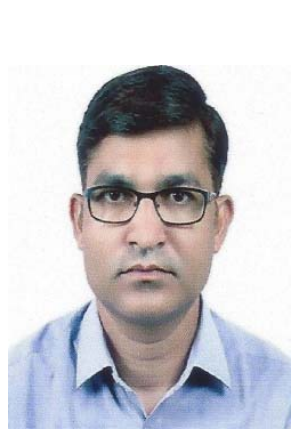

\begin{abstract}
Authors Profile
Devchand J. Chaudhari is presently working as an Assistant Professor in Computer Science and Engineering Department, Government College of Engineering, Chandrapur, (MS), India. He has 18 years of teaching experience. He received M.E. in Computer Engineering from Mumbai University, Mumbai, MS, India. He is currently pursuing $\mathrm{Ph}$. D. in Computer Science and Engineering from Saveetha Institute of Medical and Technical Sciences, (Deemed to be University), Chennai, India. He published several research papers in International conferences and reputed journals. He is a Lifetime Member of ISTE. His research interests include Image Processing, Data Mining and Machine Learning.

Dr. K. MALATHI is an Associate Professor in the Department of Computer Science and Engineering, Saveetha School of Engineering, Saveetha Institute of Medical and Technical Sciences, Chennai with 14 Years of teaching experience and 1.6 years of industry experience. She graduated her B.Tech from Anna Univeristy, M.E from Sathyabama University, and Ph.D degree in computer science in 2018 from Saveetha Institute of Medical and Technical Sciences, Chennai. Her research interests includes image processing, data mining, Medical Image Processing. She is life member in CSI, IEEE Computer Society, and IET. She has published around $60+$ research papers in reputed journals and 4 International conferences. She has received most Enthuastic Faculty Award in women's day.
\end{abstract}

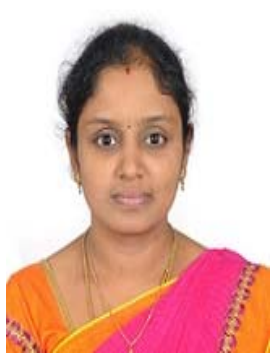

